See Article page 72.

\section{Commentary: Find the plane. Carefully dissect. Snip. Repeat. And beware the elephant!}

\author{
Gaetano Paone, MD, MHSA
}

Despite the large number of transcatheter aortic valve replacement (TAVR) procedures performed worldwide to date, relatively few reports have reported on explantation of either of the 2 most widely used valve devices. ${ }^{1-3}$ Especially when not acute, valve removal has often been described as difficult, enabled by "crushing" the valve to reduce or eliminate the outward radial force, and can be associated with damage to the aortic root and/or ascending aorta. Of concern, 2 recent series reported that operative mortality can be considerably greater than would be expected for patients undergoing both primary and redo surgical aortic valve replacement (SAVR), including those at low risk. ${ }^{2,3}$

In this issue of JTCVS Techniques, Nakazato and colleagues ${ }^{4}$ have demonstrated, with an accompanying video, a technique to facilitate the removal of a Sapien valve (Edwards LifeSciences, Sunnyvale, Calif) that includes sequentially cutting the length of the valve frame to release its radial forces. Adhesions between the valve and aortic wall are divided, with a plane developed to allow for safe placement of a wire cutter to begin the process, which continues until the length of the frame has been fully divided. The cut edge of the valve is grasped and partly wrapped around a Kelly clamp to provide countertraction, enabling the subsequent dissection and valve removal.

\footnotetext{
From the Division of Cardiothoracic Surgery, Structural Heart and Valve Center, Emory University School of Medicine, Atlanta, Ga.

Disclosures: Dr Paone is a consultant and proctor for Edwards Lifesciences and owns equity in Medtronic PLC.

The Journal policy requires editors and reviewers to disclose conflicts of interest and to decline handling or reviewing manuscripts for which they may have a conflict of interest. The editors and reviewers of this article have no conflicts of interest.

Received for publication June 14, 2020; revisions received June 14, 2020; accepted for publication June 17, 2020; available ahead of print June 23, 2020.

Address for reprints: Gaetano Paone, MD, MHSA, Division of Cardiothoracic Surgery, Structural Heart and Valve Center, Emory University Midtown Hospital, 550 Peachtree St, NE, Davis-Fischer Building, 4th Floor, Atlanta, GA 30308 (E-mail: gaetano.paone@emory.edu).

JTCVS Techniques 2020;3:77-8

2666-2507

Copyright (C) 2020 The Authors. Published by Elsevier Inc. on behalf of The American Association for Thoracic Surgery. This is an open access article under the CC BY-NCND license (http://creativecommons.org/licenses/by-nc-nd/4.0/).

https://doi.org/10.1016/j.xjtc.2020.06.035
}

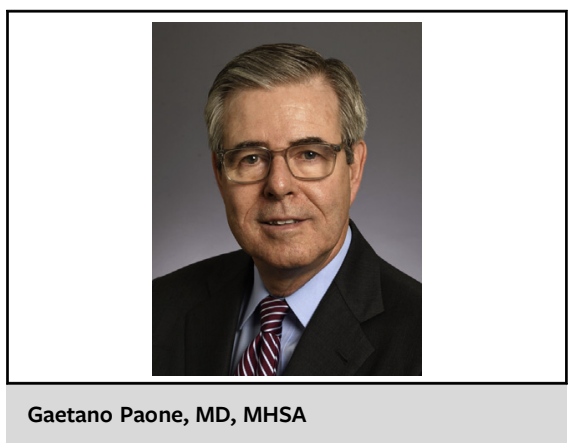

CENTRAL MESSAGE

A technique proposed to facilitate removal of a Sapien valve additionally reminds us that the treatment of patients likely to require multiple valve procedures over their lifetime remains uncertain.

Although the proposed technique seems reasonable, it is unlikely that valve removal, with or without cutting the frame, will routinely be as straightforward as depicted in the case the authors chose to illustrate this approach. No doubt, at times, it will prove far more difficult, if not impossible, to develop the dissection plane and space needed for safe placement of the requisite wire cutter. The authors seemed to acknowledge this with frequent reference to the importance of "careful" dissection to avoid damage to the aortic sinuses, coronary ostia, and mitral valve below.

With TAVR now available for essentially all patients requiring aortic valve replacement, there can be little doubt we will see an increasing number of patients who will require surgical removal of one or more of these devices. The relative technical difficulty of doing so will vary with, among other factors, the device implanted and its spatial relationship within the aortic root and ascending aorta, its proximity to the anterior leaflet of the mitral valve, the clinical indication for explantation, and the duration the implant has been in place. Cutting, not crushing, the valve frame might well, on occasion, serve as a useful adjunct. Fully recognizing how simplistic this sounds, slow and careful dissection in the right plane will help every time. Nonetheless, the authors have provided an additional technical maneuver for consideration.

Acknowledging an expected increase in these cases in the future, the authors concluded that "...careful patient 
selection is mandatory for TAVR to avoid early SVD [structural valve degeneration]." With this comment they have, perhaps inadvertently, drawn attention to the elephant in the room, namely a broader discussion of the choice between SAVR and TAVR, especially as the initial procedure, and what should, at this time, be the appropriate paradigm for treating aortic stenosis, especially in younger and lower risk patients. ${ }^{1,5,6}$

\section{References}

1. Mangi AA, Ramchandani M, Reardon M. Surgical removal and replacement of chronically implanted transcatheter aortic prostheses: how I teach it. Ann Thorac Surg. 2018;105:12-4.
2. Fukuhara S, Brescia AA, Shiomi S, Rosati CM, Yang B, Kim KM, et al. Surgical explantation of transcatheter aortic bioprostheses: results and clinical implications. J Thorac Cardiovasc Surg. January 12, 2020 [Epub ahead of print].

3. Jawitz OK, Gulack BC, Grau-Sepulveda MV, Matsouaka RA, Mack MJ, Holmes DR, et al. Reoperation after transcatheter aortic valve replacement an analysis of the Society of Thoracic Surgeons database. J Am Coll Cardiol Interv. 2020;13:1515-25.

4. Nakazato T, Toda K, Kuratani T, Sawa Y. Redo surgery after transcatheter aortic valve replacement with a balloon expandable valve. J Thorac Cardiovasc Surg Tech. 2020;3:72-4.

5. Edelman JJ, Meduri CU, Thourani VH. Commentary: aortic stenosis in young patients-planning a lifetime of aortic valve disease. J Thorac Cardiovasc Surg. January 11, 2020 [Epub ahead of print].

6. MacGillivray TE, Reardon MJ. Reoperation after transcatheter aortic valve replacement: breaking up is hard to do*. J Am Coll Cardiol Interv. 2020;13: 1526-8. 